\title{
Gamma Knife for Cerebral Arteriovenous Malformations at a Single Centre
}

\author{
F.A. Zeiler, P.J. McDonald, A. Kaufmann, D. Fewer, J. Butler, G. Schroeder, \\ M. West
}

\begin{abstract}
Background: We report the results of a consecutive series of patients treated with Gamma Knife (GK) Surgery for cerebral arteriovenous malformations (AVMs). Methods: We retrospectively reviewed 69 patients treated with GK for cerebral AVMs between November 2003 and April 2009, recording clinical data, treatment parameters, and AVM obliteration rates in order to assess our effectiveness with GK in treating these lesions. Results: Ten patients were lost to follow-up. Presentations included: seizure (24), hemorrhage (18), persistent headache (12), progressing neurological signs (10), and incidental (9). In 24 patients (34.8\%) treatment planning consisted of digital subtraction angiography (DSA), magnetic resonance imaging (MRI), and computed tomogram (CT) angiography (CTA). Currently we rely predominantly on CTA and/or MRI scanning only. Fourty-one patients have been followed for a minimum of 3 years; average age $40.9 y r ., 58.5 \%$ males. Average dose at the $50 \%$ isodose line was 20.3 Gy (range 16 to 26.4 Gy). Obliteration was observed in $87.8 \%$ by MRI, CT, or DSA. Not all obliteration was confirmed by DSA. Complications occurred in 12 of $59(20.3 \%)$ patients, and in 11 of $41(26.8 \%)$ with 3 year follow-up. Major (temporary) complications for the 59 included symptomatic cerebral edema (7), seizure (2), and hemorrhage (1). Major permanent complications occurred in one patient suffering a cranial nerve $\mathrm{V}$ deafferentation, and in two patients suffering a hemorrhage. Conclusion: GKS for cerebral AVM's offers an effective and safe method of treatment, with low permanent complication rate.
\end{abstract}

RÉSUMÉ: Le scalpel gamma dans le traitement des malformations artérioveineuses cérébrales : résultats obtenus dans un centre. Contexte : Nous décrivons les résultats obtenus chez une série de patients consécutifs traités au moyen de la radio chirurgie par scalpel gamma (SG) pour une malformation artérioveineuse cérébrale (MAV). Méthode : Nous avons révisé rétrospectivement les dossiers de 69 patients traités par SG pour une MAV cérébrale entre novembre 2003 et avril 2009. Les données cliniques, les paramètres du traitement et le taux d'oblitération de la MAV ont été colligés afin d'évaluer notre efficacité à traiter ces lésions avec le SG. Résultats : Aucune donnée de suivi n'était disponible chez dix patients. Le tableau clinique était variable : 24 patients avaient consulté pour des crises convulsives, 18 pour une hémorragie, 12 pour des céphalées persistantes, 10 pour des signes neurologiques progressifs et 9 pour des symptômes fortuits. Chez 24 patients $(34,8 \%)$ la planification du traitement a été faite par angiographie de soustraction numérique (ASN), IRM et angiographie CT (ACT). Actuellement, nous avons recours surtout à l'ACT et/ou à l'IRM seulement. Quarante et un patients, dont l'âge moyen était de 40,9 ans et dont 58,5\% étaient des hommes, ont été suivis pendant au moins 3 ans. La dose moyenne à la ligne d'isodose de 50\% était de 20,3 Gy (écart de 16 à 26,4 Gy). Une oblitération a été observée à l'IRM, au CT ou à l'ASN chez $87,8 \%$ des patients. Toutes les oblitérations n'ont pas été confirmées par ASN. Douze des 59 patients (20,3\%) ont présenté des complications de même que 11 des 41 patients $(26,8 \%$ ) chez qui nous avons un suivi de 3 ans. Les complications majeures (temporaires) observées chez certains des 59 patients étaient de l'œdème cérébral symptomatique (7), des crises convulsives (2) et une hémorragie (1). Des complications majeures permanentes sont survenues chez un patient qui a subi une désafférentation du 5e nerf et chez 2 patients qui ont subi une hémorragie. Conclusion : La radio chirurgie par SG est une méthode de traitement efficace et sûre pour traiter les MAV et le taux de complication permanente est faible.

Can. J. Neurol. Sci. 2011; 38: 851-857

The treatment of cerebral arteriovenous malformations (AVMs) has evolved over the years to include multiple different modalities. Stereotactic radiosurgery is one of the leading technologies in the treatment of AVMs, with numerous studies published demonstrating its efficacy ${ }^{1}$. Obliteration rates within the literature have been described ranging from $40-87 \%^{2-16}$. Methods of predicting treatment response also have been developed including AVM grading specific to radiosurgery ${ }^{17,18}$, and post-radiosurgery injury predictive models utilizing volume treated and AVM location?.

This study summarizes our institutional results in the treatment of cerebral AVMs with the Leksell Gamma Knife Model C and Perfexion systems between November 2003 and April 2009.

\section{METHODS}

Between November 2003 and April 2009, 69 patients with cerebral AVM underwent Gamma Knife (GK) radiosurgery at the Health Sciences Center in Winnipeg, Manitoba. We retrospectively reviewed the records of these patients and

From the Department of Neurosurgery (FAZ, MW, AMK, DF, PJM), Health Sciences

Centre; Department of Radiation Oncology (JB, GS), CancerCare Manitoba,

University of Manitoba, Winnipeg, Manitoba, Canada.

ReCeived April 7, 2011. Final Revisions Submitted June 8, 2011.

Correspondence to: Frederick A Zeiler, Department of Neurosurgery, Health Sciences

Center, University of Manitoba, GB-134, 820 Sherbrook Street, Winnipeg, Manitoba,

R3A 1R9, Canada. 
recorded data up to November 2010 on: age, sex, AVM diameter and volume, GK treatment parameters, complications, time until AVM response (defined as change in nidus size on follow up imaging), AVM obliteration (defined as absence of nidus on follow up imaging), and clinical outcomes. Ethics approval was obtained for the study by the Health Research Ethics Boards, at the University of Manitoba.

\section{RESUlts}

\section{Demographics}

Basic demographic characteristics of the patient population with follow up, and the sub-population with three years follow up is displayed in Table 1 below. (left hand paresthesia (1), left leg paresthesia/paresis (1), and left hemiparesis (2)), right hemiparesis in one patient, and right arm paresthesia in two patients). Twelve patients had persistent headaches over many years, with seven patients having headaches in isolation. Finally, nine patients were asymptomatic, in which the AVM was discovered incidentally during investigation for symptoms unrelated to the AVM.

Average AVM diameter and volume was $2.37 \mathrm{~cm}$ and 4.68 cubic centimetres, respectively. The locations of the AVM were widely dispersed across the cortical surface and within the deeper brain structures. There were 69 AVM covering a total of 80 central nervous system (CNS) locations (eleven AVM covering two surfaces). These regions included: 19 frontal, 15

\begin{tabular}{|c|c|c|}
\hline Demographic Category & $\begin{array}{l}\text { Total Patient Population With Follw- } \\
\qquad U p(n=59)\end{array}$ & Three Year Follow-Up Group $(n=41)$ \\
\hline Age (years) & $14-72$ (average: 38.4 ) & 14-74 (average: 40.9 ) \\
\hline \multirow{3}{*}{$\begin{array}{ll}\text { Sex } & \text { Male } \\
& \text { Female } \\
\text { Average AVM Total Volume }\left(\mathrm{cm}^{3}\right)\end{array}$} & 31 & 24 \\
\hline & 28 & 17 \\
\hline & 4.90 & 5.05 \\
\hline Average AVM Diameter (cm) & 2.32 & 2.36 \\
\hline Average \% Coverage & 98.3 & 98.3 \\
\hline Average SM Grade & 2.5 & 2.5 \\
\hline Average Pollock Grade & 1.56 & 1.68 \\
\hline Average $50 \%$ Isodose Line Dose (Gy) & 20.5 & 20.3 \\
\hline Average Time Until AVM change (months) & 11.7 & 12.6 \\
\hline Total Number Obliterated & 36 & 36 \\
\hline Total Number of Serious Complications & 12 & 11 \\
\hline
\end{tabular}

Of the 69 patients treated, 61 were treated the Leksell Gamma Knife model C, and eight were treated with the Leksell Gamma Knife Perfexion system. Five patients received two treatments for their AVM due to: lack of response to previous GK treatment at our institution (or from another) in three, and staged treatment due to large AVM size in two. Four patients had previous treatment for their AVM at other institutions: two had GK elsewhere, one had an embolization attempt, and one had an embolization and partial surgical resection. Four of the forty-one patients with three years of follow received two treatments. Two had planned staged therapy for large AVM, and the other two due to initial treatment failure. The average age of the population was 38.6 years, with 39 male $(56.5 \%)$ and 30 female $(43.5 \%)$ patients.

Twenty-four patients had a history of seizures as their clinical presentation. Eighteen presented with hemorrhage. Ten patients presented with a history of progressive neurological deficits including: left sided hearing loss in one patient, left visual flashing in two, left paresthesia and/or paresis in four patients temporal, 12 parietal, 17 occipital, 5 cerebellar, 3 brainstem, 7 basal ganglia, and 2 midline lesions.

Of the 69 patients treated with GK for their AVM, ten patients, all of whom were referred from outside centers, were lost to follow up. Attempts to contact these patients were made by telephone on a minimum of three occasions with no success. In addition, request was sent to their referring physician for further follow up data. However in all cases these patients were discharged from further follow up care, or did not return to their referring physician for post treatment follow up. Table 2 describes the clinical features of these ten patients. As of last known follow up, none of these patients had died. Attempts were made by phone on multiple occasions to achieve contact with the patients, however all were unsuccessful. As a result, the remainder of the review focused on the two following groups: 59 patients with follow-up ongoing and the 41 patients with a minimum of three years follow up as of November 2010.

Treatment parameters for the GK consisted of max dose ranging from 32 to $48 \mathrm{~Gy}$, with average dose to the $50 \%$ isodose 
of 20.3 Gy (range: $16-26.4$ Gy). The mean coverage was 98.2\% (range: $87-100 \%$ ), with the average of 11.6 isodose centers (range: $1-28$ ). Computerized tomographic angiography (CTA), and magnetic resonance imaging (MRI) were used in treatment planning in all patients. In 24 patients $(34.8 \%)$ treatment planning consisted of a combination of digital subtraction angiography (DSA), magnetic resonance imaging (MRI) scanning, and CTA. More recently we have relied mainly on CTA and/or MRI scanning in treatment planning such that in 45 patients $(65.2 \%)$ planning was conducted without the use of DSA. All patients, however, did have a DSA as part of their initial diagnostic work up. Treatment planning and dose assignment were conducted by a neurosurgeon, radiation oncologist, and medical physicist.

Forty-one patients had a minimum of three years of follow-up documented, and were the major focus of our study. We had defined three years as a sufficient period of time to allow for AVM response. Of these patients with at least three years of follow up the average age was 40.9 years, with 24 male and 17 female. The average diameter and volume of the AVMs for this subgroup was $2.36 \mathrm{~cm}$ and 5.05 cubic centimetres respectively. Locations of these AVM include: nine frontal, ten temporal, six parietal, nine occipital, four cerebellar, two brainstem, six basal ganglia, and one midline. Six of the AVM covered two cortical locations.

Follow-up clinic visits were conducted at six to eight weeks post treatment. Imaging was conducted at one, two, and three years post treatment with MRI or CTA. Initially, when either MRI or CTA demonstrated the absence of an AVM nidus, subsequent digital subtraction angiography (DSA) was conducted in order to determine AVM patency or obliteration. However, more recently we have relied on MRI and/or CTA alone to demonstrate obliteration, in the absence of the use of DSA. Avoiding the use of DSA was based on the literature demonstrating the efficacy of MRI and its ability to predict AVM patency ${ }^{19}$.

\section{Arteriovenous Malformation Obliteration Rates}

We defined AVM obliteration as the absence of an AVM on any of MRI, CTA, or DSA. Of a total of 59 patients with follow up, our results demonstrated obliteration in 36 of 59 patients (61.0\%). In these 36 patients demonstrating obliteration, 20 displayed the absence of any AVM nidus on MRI/CTA and DSA.

The remaining 16 patients demonstrated absence of the AVM on MRI and/or CTA only. Average time until either imaging or angiographic change in AVM size was 11.7 months. This change in imaging appearance was defined as the first sign of AVM change in size on regular scheduled follow up imaging. Only one patient demonstrated MRI obliteration, with subsequent completed DSA demonstrating small residual AVM. This patient underwent repeat GK treatment. An example of our angiographic response with GK is displayed in Figure 1, while our MRI response can be seen in Figure 2.

In those patients with three years of follow-up, the overall obliteration rate was 36 of $41(87.8 \%)$. Twenty-three of 41 had a DSA in their post treatment follow up. The average time until imaging change in this sub-group was 12.6 months, with only one patient out of 41 failing to demonstrate any change in AVM size at the three year mark. The average time until obliteration was 27.6 months. The patient failing to demonstrate AVM response to treatment was a 29 year old male, with a left frontal Spetzler-Martin (SM) grade 2 AVM who had a head CT to investigate left blepharospasm and blurred vision. The thirty seven patients with three years of follow up and single GK

Table 2: Characteristics of ten patients lost to follow-up

\begin{tabular}{llllll}
\hline Sex & Age & Presentation & Location & SM Grade & Diameter of AVM (cm) \\
\hline M & 25 & GM Sz & Rt Frontal & 2 & 2.32 \\
M & 22 & Lt hearing loss & Lt CP angle & 3 & 1.68 \\
M & 38 & H/A 5 years, LOC & Rt Temporal-parietal & 4 & 3.90 \\
M & 18 & Lt hemisphere bleed & Lt Lentiform & 3 & 2.80 \\
M & 54 & Complex Partial Sz & Lt Temporal & 3 & 1.21 \\
F & 25 & GM Sz, Rt sensory changes & Lt Parietal & 3 & 3.32 \\
M & 68 & Rt ataxia, hemiparesis & Lt Parietal & 3 & 2.32 \\
M & 49 & GM Szx2 & Lt Occipital & 2 & 1.32 \\
F & 55 & Rt hemisensory loss, hemiparesis & Lt Fronto-parietal & 2 & 1.31 \\
M & 18 & Leisodes & & 2 \\
\hline
\end{tabular}

$\mathrm{M}=$ Male, $\mathrm{F}=$ Female, $\mathrm{GM}=$ Grand Mal, $\mathrm{Sz}=$ seizure, $\mathrm{H} / \mathrm{A}=$ headache, $\mathrm{Rt}=$ right, $\mathrm{Lt}=$ left, $\mathrm{SM}=$ Spetzler-Martin, $\mathrm{AVM}=$ arteriovenous malformation, $\mathrm{LOC}=$ loss of conciousness, $\mathrm{CP}=$ cerebellar-pontine 


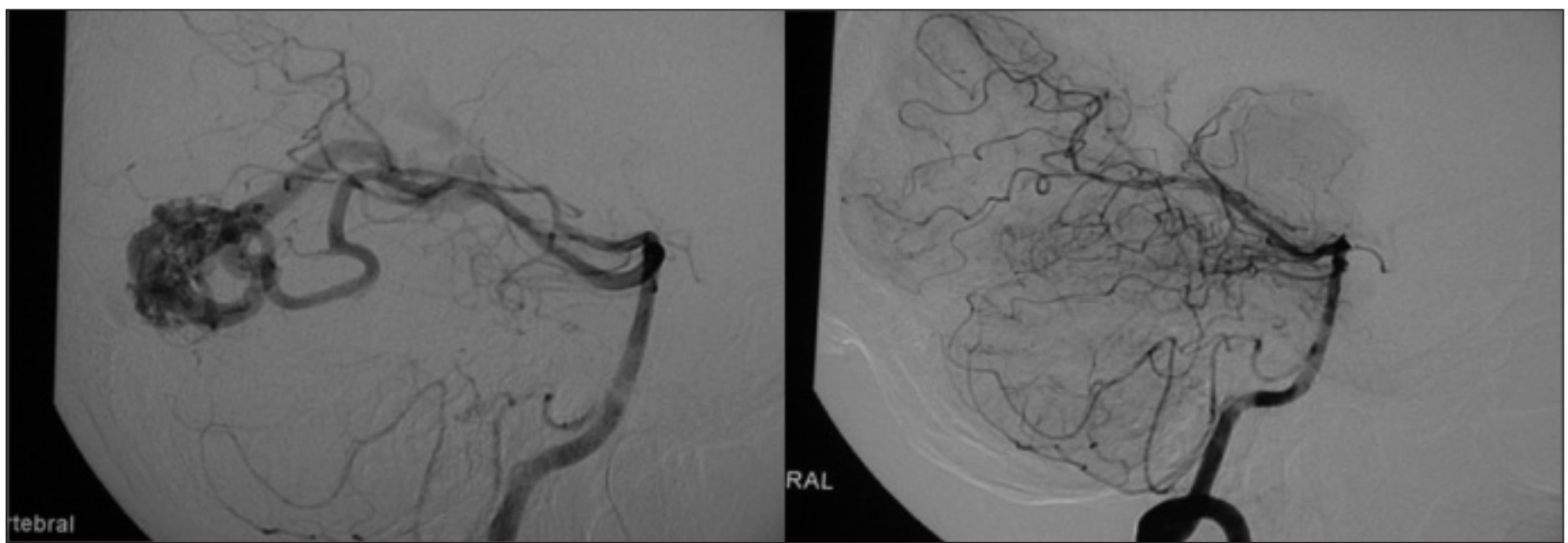

Figure 1: DSA of Right Occipital AVM in 47 Year Old Male. DSA = digital subtraction angiogram, AVM = arteriovenous malformation. The image above displays a right occipital AVM on DSA of the right vertebral artery, both before (on left) and after (on right) treatment with Gamma Knife. Of note is the complete absence of the AVM nidus and dilated draining veins on the post treatment DSA (on right), with a total of 29 months between the two images.

treatment demonstrated obliteration in 35 of 37 cases $(94.6 \%$ obliteration rate).

The average Spetzler-Martin (SM) grades $^{20}$ and Pollock grades $^{17,18}$ were 2.5 and 1.68 respectively, in the three year follow-up group. Obliteration rates correlated with the SM and Pollock grades as shown in Table 3 and 4. Table 3 represents Spetzler-Martin grades of: 1, 2, 3 and 4 and the corresponding obliteration rates of $100.0 \%, 88.9 \%, 90.5 \%$, and $50.0 \%$ respectively. While Pollock grades (Table 4 ) of: less than 1,1 to 2 , and greater than 2 displayed obliteration rates of $85.7 \%$, $90.9 \%$, and $75.0 \%$ respectively.
Of the five patients with two or more Gamma Knife treatments: one was among the group of patients with inadequate amount of follow up, three demonstrated a persistent AVM nidus on imaging, while one demonstrated obliteration on MRI.

\section{Complications of GK Radiosurgery}

The overall number of complications described in 59 patients was $12(20.3 \%)$ serious complications, and 14 (23.7\%) minor complications. We defined major complications as those that caused the patient clinical deficit enough to require either emergency room visit or non-scheduled imaging as an

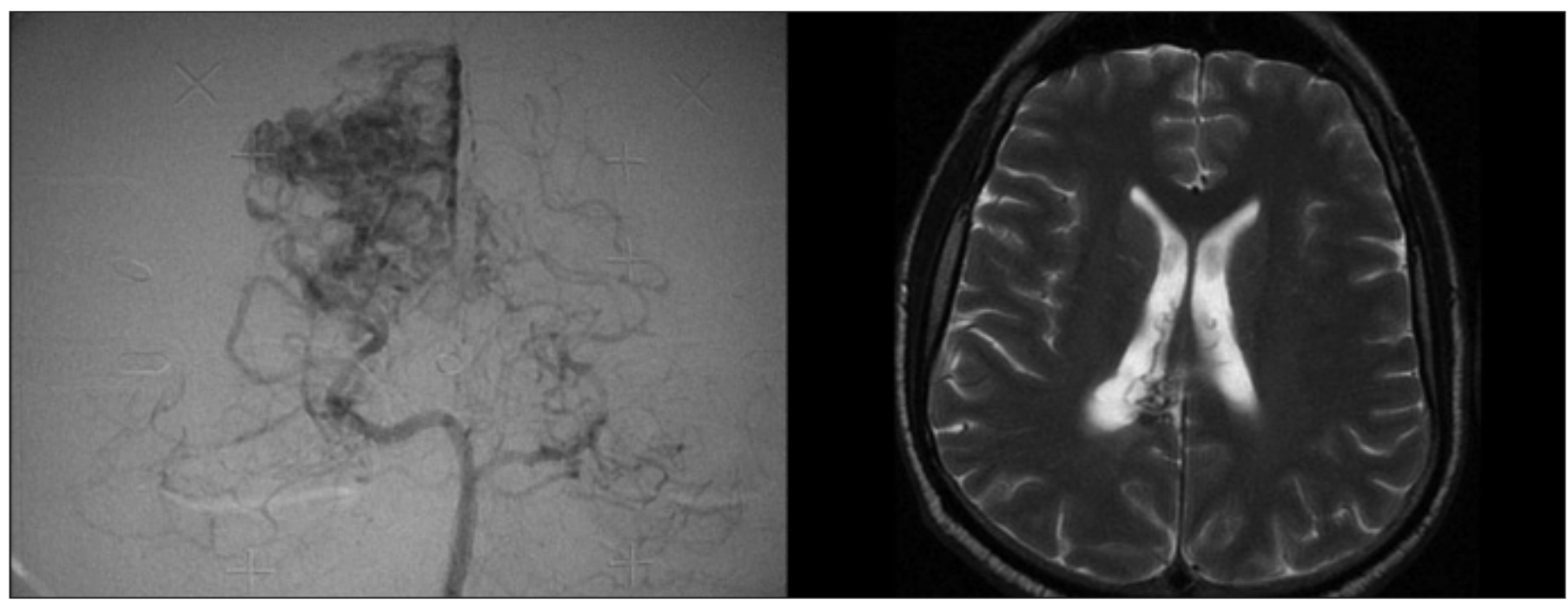

Figure 2: DSA and 18 Month MRI Follow-Up of Right Occipital AVM in 51 Year Old Male. DSA = digital subtraction angiogram, AVM = arteriovenous malformation. The above image displays pre-Gamma Knife DSA of right occipital AVM (on left), and 18 month post-GK MRI follow-up imaging(on right). Of note is the complete absence of the AVM nidus on follow-up MRI, with small dilated veins in the right lateral ventricle. The patient eventually went on to demonstrate DSA obliteration at 39 months. 
Table 3: Spetzler-Martin Grades and obliteration rates for three year follow-up group

\begin{tabular}{ccccc}
\hline Spetzler Martin Grade & Number of Patients & $\begin{array}{c}\text { \% of AVMs } \\
\text { Obliterated }\end{array}$ & Clinical Outcome & Complications (\%) \\
\hline 1 & 7 & 100.0 & All ASx & 42.9 \\
2 & 9 & 88.9 & 6 ASx; 3 persistent Sx & 22.2 \\
3 & 21 & 90.5 & 14 ASx; 6 persistent Sx; & 42.1 \\
4 & 4 & 1new deficit & 25.0 \\
5 & 0 & 50.0 & 4 ASx & N/A \\
\hline
\end{tabular}

$\mathrm{AVM}=$ Arteriovenous Malformation, $\mathrm{ASx}=$ asymptomatic, persistent $\mathrm{Sx}=$ persistent pre-treatment symptoms, N/A = Not applicable due to no patients in category. Complication \% excluded pin site edema and localized balding.

outpatient. Major complications included: two patients with post-treatment cerebral hemorrhage, seven patients with symptomatic cerebral edema, two patients with new onset seizures, and one patient with cranial nerve $(\mathrm{CN}) \mathrm{V}$ deafferentation defect (see below for further description). Symptomatic cerebral edema was defined as clinical presentation with headache or focal neurological signs with imaging documenting treatment site edema. None of the patients with symptomatic cerebral edema had permanent deficits as a result of this complication. Minor complications consisted of the following: eight patients with asymptomatic cerebral edema, localized alopecia at treatment site in one patient, and five patients with stereotactic frame pin site edema. Asymptomatic cerebral edema was defined as localized treatment site edema noted on regular follow up imaging, in the absence of clinical manifestations. Of note, none of the above described complications were fatal.

In the three year follow-up subgroup, the overall complication rate was 11 of $41(26.8 \%)$ for serious complications, and 8 of 41 (19.5\%) for minor complications. Major complications included: seven patients with symptomatic cerebral edema, one patient new onset seizure disorder requiring antiepileptic therapy for which the patient was currently on as of last follow up at 5.5 years from GK, two post-treatment hemorrhages(one resulting in permanent deficits), and finally one patient with $\mathrm{CN} \mathrm{V}$ deafferentation injury. Minor complications included: four patients with asymptomatic cerebral edema, two patients with stereotactic frame pin site edema, and two with localized alopecia.

All of the above outlined complications of GK treatment were temporary, except for three. Permanent deficits were seen in three patients. One patient with a post-treatment hemorrhage had persistent left sided hemiparesis. This patient was a 38 yearold male, with a $3.90 \mathrm{~cm} \mathrm{SM}$ grade 4 right temporal-parietal AVM, who was subsequently lost to follow up. Last follow up contact was by phone at 20 months post-treatment and 19 months post-hemorrhage. The second, a 72 year-old female with a presenting history of trigeminal neuralgia, noted to have an AVM of SM grade 3 , with a diameter $1.35 \mathrm{~cm}$. The patient received repeat GK for persisting AVM that included the trigeminal nerve root. This patient suffered permanent $\mathrm{CN} \mathrm{V}$ deafferentation, clinically consisting of numbness in V1 and V2 sensory distributions and occasional numbness and dysesthesia in V3. This dysesthetic sensory deficit is described by the patient as different than her underlying trigeminal neuralgia (a more burning/numb quality, as opposed to lancinating). Third, was a 35 year old male with a left sided perimesecephalic AVM, who initially presented with hemorrhage into his basal cisterns. Post

Table 4: Pollock Grades and obliteration rates for three year follow-up group

\begin{tabular}{|c|c|c|c|c|}
\hline Pollock Grade & Number of Patients & $\begin{array}{l}\% \text { of AVMs } \\
\text { Obliterated }\end{array}$ & Clinical Outcome & Complications (\%) \\
\hline$<1$ & 7 & 85.7 & 4 ASx; 3 persistent Sx & 28.6 \\
\hline $1-2$ & 22 & 90.9 & $\begin{array}{c}16 \text { ASx; } 5 \text { persistent Sx; } \\
\text { 1new deficit }\end{array}$ & 36.4 \\
\hline$>2$ & 12 & 75.0 & 9 ASx; 2 persistent $S x$ & 58.3 \\
\hline
\end{tabular}

$\mathrm{AVM}=$ Arteriovenous Malformation, $\mathrm{ASx}=$ asymptomatic, persistent $\mathrm{Sx}=$ persistent pre-treatment symptoms.

Complication \% excluded pin site edema and localized balding. 
treatment, he had MRI and CTA evidence of obliteration, and subsequently refused DSA for follow up. He then suffered a hemorrhage into his brainstem resulting in right hemiplegia, left intranuclear ophthalmoplegia, and pendular nystagmus. Digital subtraction angiography conducted post re-bleed failed to demonstrate the presence of an AVM nidus. Currently he is receiving physiotherapy, with Glasgow Outcome Score (GOS) of 3 .

\section{Clinical Outcomes}

Clinically 12 of 59 patients overall had persistence of their pre-GK symptoms (as of their last documented follow-up) despite treatment with or without AVM response. These persistent symptoms included: ataxia in four patients, right sided hemiparesis in one patient, one patient with right arm weakness, one patient with left leg weakness, one patient with left dysesthesias, one patient with dysphasia, left non-specific intermittent visual field cut in one patient, right superior quandrantanopsia in one patient, and persistent headache in one patient.

Fourteen patients out of the 59 developed transient neurological deficits composed of the following: three with left facial numbness, one with right arm weakness, two with left sided weakness/paresthesia, four with ataxia, one left leg weakness, one with mild expressive aphasia, and two with headache and vertigo. Only 3 of these 14 patients had radiographic evidence of radiation necrosis on MRI. The deficits manifested during the first 12 months in all patients. All of these patients made a complete recovery from the above mentioned transient deficits.

In the three year follow-up subgroup, nine patients had persistent pre-operative symptoms including: three patients with ataxia, one patient with right hemiparesis, one patient with right arm paresis, one patient with left leg paresis, one patient with ongoing headache, and two patients with ongoing short term memory loss (STM).

Overall, in those patients included in the three year follow-up subgroup, the average follow-up time for each patient was 43.1 months. Average GOS, determined from data of last follow-up visit, was 4.8. Thirty-eight out of 41 patients $(92.3 \%)$ had a GOS of 5, with only eight having minor residual problems (all persistent pre-operative symptoms). One patient $(2.4 \%)$ had a GOS of 4 as a result of persisting pre-operative deficits (right homonymous hemianopsia). Finally, two patients had a GOS of 3. One as a result of pre-operative deficits, leaving the patient with complete right sided hemiparesis that has failed to improve. The second, a patient whom suffered a major rebleed into their brainstem, resulting in multiple cranial neuropathies and dense hemiparesis that has improved but remains severely disabling.

\section{Seizure Responsiveness}

Of particular note, is the effect of GK radiosurgery on those patients presenting with seizures. In 69 patients total, 24 patients had a history of seizure, four being lost to follow-up. The remaining 20 patients with follow-up noted only one patient with seizures persisting post treatment. Eleven of the 20 patients are still currently on anti-epileptic drugs, with the one patient having refractory seizures on medication.

\section{Discussion}

Radiosurgery for cerebral AVM has demonstrated efficacy in the literature, with obliteration rates varying from $40-87 \%$. Our obliteration rate of $87.8 \%$ in those with three years of follow-up demonstrates a good response. Analyzing those patients with single GK therapy and three years of follow-up, our obliteration rate is $94.6 \%$.

The overall major complication rate was 11 of $41(26.8 \%)$ in the three year follow-up subgroup, and 13 of 59 in the total population with follow up. Permanent complications occurred in three out of the 69 patients studied. The bulk of these complications were related to symptomatic local treatment site edema. Only two patients out of 59 with follow-up retained permanent deficits as a result of GK complications, as described previously. One patient lost to follow-up had permanent deficits resulting from post-treatment hemorrhage, as of their last follow-up data. Recurrent hemorrhage post treatment occurred in only three patients, with two developing permanent deficits (one lost to follow-up).

Clinical outcome is good in our patient group with only 15 of $59(25.4 \%)$ continuing to have persistent pre-operative symptoms despite treatment, with/without AVM response. Patients presenting with seizures as a clinical manifestation had a good response to treatment, with all but one being seizure-free as of their last follow up appointment, with 4 of 24 having inadequate follow-up. However, the majority $(11 / 20)$ are still on antiepileptics as of their last clinical contact. This result is good in comparison to the majority of series quoting a $50 \%$ seizure free rate, with the predominance of those patients on antiepileptics $^{21}$.

Our post-radiosurgery AVM obliteration rates are at the high end of the range previously described in the literature. In analyzing the institutional results, we come upon a few strong factors that contribute to our favourable results. First, of all patients treated, the $50 \%$ isodose line dose was 16 Gy or greater. This is important, due to literature recommendations that treatment doses any lower do not result in significant AVM response $^{8,9}$. Conversely, we only treated one patient with a $50 \%$ isodose line dosage above $25 \mathrm{~Gy}$, as per literature documentation of the lack from benefit to higher doses, with increased complication rates ${ }^{8}$. Second, we utilized multiple collimator shots, average 11.6, and strived to achieve tight comformality in every treatment plan. Third, utilizing the significant postradiosurgery injury evaluation (SPIE) model of predicting injury post radiosurgery, developed by Flickinger et $\mathrm{al}^{7}$, we were able to minimize the 12 Gy volume as much as possible in those at predicted risk for complications, thus minimizing our adverse outcomes. Finally, only two out 69 patients had previous embolization attempts prior to GK radiosurgery. This is an important factor in AVM response, as documented by AndradeSouza et $\mathrm{al}^{2}$ and Back et $\mathrm{al}^{5}$, as there exists a decreased response rate in AVMs previously treated with endovascular embolization. Yet, despite the aforementioned positive results, the loss of 10 of 69 patients $(14.5 \%)$ to follow-up makes definitive statements on our experience with GK for AVM. Despite multiple attempts to contact these patients, we were unsuccessful. This is a definite limitation to our retrospective analysis.

In addition, defining obliteration as the absence of AVM on any of MRI, CTA, or DSA in our study can be considered 
controversial. However, DSA as the gold standard in documenting AVM obliteration may not always be possible. In our population for example, some patients demonstrated AVM absence on MRI, however due to co-morbid medical conditions were not able to undergo DSA. In addition, some patients refused DSA after being informed of the potential nephrologic and neurologic complications of the procedure. Pollock et el ${ }^{19}$ described the efficacy of MRI alone in being able to predict AVM obliteration, approaching approximately $91 \%$ with sufficient response time to treatment allowed. Thus, with this study demonstrating the efficacy of MRI in predicting AVM obliteration, and the ever improving resolution of CTA and MRI, we felt that overall we would only minimally overestimate our obliteration rate. As well, with the results of Yen et $\mathrm{al}^{22}$ and Pollock et $\mathrm{al}^{23}$ demonstrating no change in the natural history of partially treated AVMs with GK surgery (in terms of no increase in hemorrhage rate from natural history), we feel more comfortable leaving a small persistent nidus not picked up on MRI or CTA, despite having one patient lacking angiographic confirmation of obliteration that subsequently developed major re-bleed resulting in significant disability. However, it has been advocated that retreatment of an AVM can afford an obliteration rate approaching $67 \%$, with low complication rates ${ }^{24}$.

\section{Conclusions}

We have presented the results of a single Canadian centre's experience treating cerebral AVM's with Gamma Knife radiosurgery, with AVM obliteration rates of $87.8 \%$ after three years follow-up. Gamma Knife radiosurgery for cerebral AVMs continues to prove itself as an effective and safe treatment modality, with high obliteration rates and low permanent complication rates.

\section{REFERENCES}

1. Starke RM, Komotar RJ, Hwang BY, et al. A comprehensive review of radiosurgery for cerebral arteriovenous malformations: outcomes, predictive factors, and grading scales. Stereotact Funct Neurosurg. 2008; 86: 191-9.

2. Andrade-Souza YM, Ramani M, Scora D, et al. Embolization before radiosurgery reduces the obliteration rate of arteriovenous malformations. Neurosurgery. 2007; 60: 443-52.

3. Andrade-Souza YM, Ramani M, Scora D, et al. Radiosurgical treatment for rolandic arteriovenous malformations. J Neurosurg. 2006;105:689-97.

4. Andrade-Souza YM, Zadeh G, Scora D, et al. Radiosurgery for basal ganglia, internal capsule, and thalamus arteriovenous malformation: clinical outcome. Neurosurgery. 2005; 56: 56-63.

5. Back AG, Vollmer D, Zeck O, et al. Retrospective analysis of unstaged and staged Gamma Knife surgery with and without preceding embolization for the treatment of arteriovenous malformations. J Neurosurg. 2008; 109(Suppl): 57-64.

6. Douglas JG, Goodkin R. Treatment of arteriovenous malformations using gamma knife surery: the experience at the University of Washington fromm 2000 to 2005. J Neurosurg. 2008; 109: 51-6.
7. Flickinger JC, Kondziolka D, Lunsford LD, et al. Development of a model to predict permanent symptomatic postradiosurgery injury for arteriovenous malformation patients. Int $\mathrm{J}$ Radiat Oncol Biol Phys. 2000; 46: 1143-8.

8. Flickinger JC, Kondziolka D, Maitz AH, et al. An analysis of the dose-response for arteriovenous malformation radiosurgery and other factors affecting obliteration. Radiother Oncol. 2002; 63: 347-54.

9. Flickinger JC, Pollock BE, Kondziolka D, et al. A dose-response analysis of arteriovenous malformation obliteration after radiosurgery. Int J Radiat Oncol Biol Phys. 1996; 36:873-9.

10. Hadjipanayis CG, Levy EI, Niranjan A, et al. Stereotactic radiosurgery for motor cortex region arteriovenous malformations. Neurosurgery. 2001; 48: 70-6.

11. Liscák R, Vladyka V, Simonová G, et al. Arteriovenous malformations after Leksell gamma knife radiosurgery: rate of obliteration and complications. Neurosurgery. 2007; 60: 1005-14.

12. Maruyama K, Shin M, Tago M, et al. Gamma knife surgery for arteriovenous malformations involving the corpus callosum. Neurosurgery. 2005; 102(Suppl): 49-52.

13. Pollock BE, Gorman DA, Brown PD. Radiosurgery for arteriovenous malformations of the basal ganglia, thalamus, and brainstem. J Neurosurg. 2004; 100: 210-4.

14. Shin M, Maruyama K, Kurita H. Analysis of nidus obliteration rates after gamma knife radiosurgery for arteriovenous malformations based on long-term follow up data: the University of Tokyo experience. J Neurosurg. 2004; 101: 18-24.

15. Young C, Summerfield R, Schwartz ML, et al. Radiosurgery for arteriovenous malformations: the University of Toronto experience. Can J Neurol Sci. 1997; 24(2): 99-105.

16. Zadeh G, Andrade-Souza YM, Tsao MN, et al. Pediatric arteriovenous malformations: University of Toronto experience using sterotactic radiosurgery. Childs Nerv Syst. 2007; 23: 195-9.

17. Pollock BE, Flickinger JC. A proposed radiosurgery-based grading system for arteriovenous malformations. J Neurosurg. 2002; 96 : $70-85$.

18. Pollock BE, Flickinger JC. Modification of the radiosurgery-based arteriovenous malformation grading system. Neurosurgery. 2008; 63: 239-43.

19. Pollock BE, Kondziolka D, Flickinger JC, et al. Magnetic resonance imaging: an accurate method to evaluate artiovenous malformations after stereotactic radiosurgery. J Neurosurg. 1996; 85: 1044-9.

20. Spetzler RF, Martin NA. A proposed grading system for arteriovenous malformations. J Neurosurg. 1986; 65: 476-83.

21. Schauble D, Cascino GD, Pollock BE, et al. Seizure outcomes after stereotactic radiosurgery for cerebral arteriovenous malformations. Neurology. 2004; 63: 683-7.

22. Yen CP, Varady P, Sheehan J. Subtotal obliteration of cerebral arteriovenous malformations after gamma knife surgery. J Neurosurg. 2007; 106: 361-9.

23. Pollock BE, Flickinger JC, Lunsford LD. Hemorrhage risk after stereotactic radiosurgery of cerebral arteriovenous malformations. Neurosurgery. 1996; 38: 652-9.

24. Mirza-Aghazadeh J, Andrande-Souza YM, Zadeh G, et al. Radiosurgical retreatment for brain arteriovenous malformation. Can J Neurol Sci. 2006; 33: 189-94. 